\title{
Mechanism and theories for Delayed Onset of Muscle Soreness in athletes
}

\author{
Mallika Bitra $^{1^{*}}$ and Preethi Rajesh ${ }^{2}$
}

\author{
${ }^{1}$ Assistant Professor, Department of Physiotherapy, School of Health Sciences \\ Garden City University, Bangalore, Karnataka, 560049. \\ ${ }^{2}$ Professor, School of Sciences, Garden City University, Bangalore, Karnataka, 560049. \\ E-mail: physio108@gmail.com; preethirajesh@gardencity.university \\ *Corresponding Author: Assistant Professor Mallika Bitra; physio108@gmail.com
}

\begin{abstract}
The sensation of tenderness and tightness over the muscle, post eccentric exercise is called Delayed Onset of Muscle Soreness (DOMS). It is not an acute pain. Post exercise the soreness will develop within 24-72 hours of duration, slowly the soreness will reduce by 5-7 days post exercise. Initially Theodre Hough, mentioned soreness will develop when an untrained muscle does a contraction opposite to the strong spring. The aim of this review article is to find out the various mechanisms and theories for Delayed Onset of Muscle Soreness development. A direct search of journals was conducted to identify the potential articles. Online search engines such as PubMed, Google Scholar, MEDLINE, and Physiotherapy Evidence-based Database (PEDro) were searched. Based on the available research studies, Delayed onset of muscle soreness developmental mechanism was understood. Literature search helped to understand the various theories on development of DOMS and physiology behind the soreness. Still more articles and research must emerge to provide the clear evidence on theories on Delayed Onset of Muscle Soreness.
\end{abstract}

Keywords: delayed onset of muscle soreness; muscle soreness; mechanism of soreness; theories of soreness; exercise induced pain

\section{INTRODUCTION}

Pain after the exercise is experienced by many people very commonly, tenderness may be felt immediately or late. A sudden exercise which is not accustomed by the individual, done by a normal or elite athlete may lead to pain and tenderness in the skeletal muscle. There are three types of pain in relation to exercise. 1. pain experienced during or immediately following exercise, 2. delayed onset muscle soreness, and 3. pain induced by muscle cramps. Pain after the exercise is called as exercise induced pain. Aetiology and time course for the development of each type of pain is different.[1] Post exercise pain may not be observed immediately, after 24 hours pain will appear as a soreness and it would go to peak pain and tightness by 72 hours post exercise. [2] Gradually pain will be lowered and disappears by 5-7 days post exercise. [3] This kind of exercise induced pain post exercise is called as Delayed onset of muscle soreness (DOMS). It is very commonly experienced by athletes. The aim of this study is to know the mechanism behind the soreness and relevant theories, explaining about soreness and the impact of this soreness in athletic performance. To achieve the aim, review was conducted to know the various available literature, research articles on mechanisms and theories of DOMS.

\section{LITERATURE REVIEWED}

An extensive literature search was done. A direct search of journals was conducted to identify the potential articles. Online search engines such as PubMed, Google Scholar, MEDLINE, and Physiotherapy Evidence-based Database (PEDro) were searched. Based on the available research studies, Delayed onset of muscle soreness developmental mechanism was understood. The keywords used included: Delayed onset of muscle soreness, Mechanism of soreness, Muscle soreness, Theories of soreness, Exercise induced pain. The articles which are not published in English were excluded. Article that focused their study on physiological, biochemical effects of DOMS were included. The articles that are focused on psychological effects of DOMS were not included. The guidelines followed for the inclusion of the articles are i. the article must have explained any theory or mechanism of DOMS, ii. the article was conducted on normal population/ athletes, iii. the articles, if reviewed previous literature on DOMS.

\section{DELAYED ONSET OF MUSCLE SORENESS}

Delayed onset of muscle soreness cardinal signs and symptoms are pain, decreased range of motion, decrease in muscle strength, and change in biochemical markers. ${ }^{[4]}$ Hough T. was the first one to print a primary report on muscle soreness and he conducted an ergographic investigation to know the types of soreness. One kind of soreness appear post exercise but will persist only for few hours and later it will subside. The aetiology for these kinds of pain may be pressure from the swollen muscle fibre, on the sensitive nerve ending or sometimes may be because of the chemical stimulation of the nerve endings. 
Where in another kind of soreness pain will persist for more than ten to twenty hours, this might occur because of tension within the muscle, leads to rupture of the muscle fibres or surrounding tissue, tension would transfer to the tendon.[5] Generally tenderness is in the distal portion of the muscle. [6]

Activity which is done in a regular pattern and in specific amount of intensity or force does not create any soreness. However, if the unfamiliar and high force is introduced for muscle work, such as sudden eccentric work, it will lead to DOMS. In this eccentric muscle activity, muscle will be elongated during unfamiliar strenuous muscle action. If the external load is going beyond the bearability of a muscle, then muscle is forced to elongate and generates active tension. ${ }^{[7]}$ As tension at motor unit level increases, disruption of actin myosin filaments bonding cause more energy utilization for separation of cross bridges, it may cause risk of injury at myotendinous junctions. For studies to conduct, researcher can induce the DOMS by introducing several eccentric activities, such as downhill running, resisted cycling, ballistic stretching, isokinetic dynamometry, and eccentric resistance exercise by using various exercise inducing protocols. $[8,9]$

\section{MECHANISM AND PROTOCOLS FOR DOMS}

There are few protocols which will use various levels of intensity, velocity, and duration of eccentric contraction to produce a significant DOMS. Some protocols may use eccentric hamstring work or eccentric biceps curls for example. Initially researcher must check 1RM of an individual to start the protocol. In case of fatigue, we must notice the levels of performance and soreness.[10] Dynamic isotonic exercise is designed by Jones and Newham, it can be performed with the help of isokinetic exercise machine also to get exercise induced soreness. Some other protocols will use the stepping down from a bench exercise mechanism to produce eccentric muscle activity. ${ }^{[11]}$ To produce DOMS in quadriceps, subjects were instructed to perform 40 maximum eccentric contractions of quadriceps.[12] By performing downhill running for 45 minutes will produced DOMS. Downhill inclination was not specific though. The high variability is seen in box and bench stepping protocol. [13] To produce DOMS in biceps dumbbell curls also used as a protocol, experiment was done to sees how many curls subjects were able to perform repeatedly. [14]

As a result of an exercise induced protocol, muscle activity will be elevated. Increased muscle activity will be associated with i. increased contractile tension which will cause muscle damage to the structural components, ii. increased metabolic activity will lead to production of waste substances, iii. muscle temperature would be increased, may cause structural damage to the tissues, iv. Neural control of the muscle will be altered because of the sudden injury, producing pain and tenderness.[15]

\section{THEORIES OF DOMS}

DOMS pain stimulus development is explained by number of theories. As a result of eccentric mechanism and tension created during the exercise will result in physiological changes. These changes are meniscule tears to muscle tissue which leads to discharge of chemicals. The chemical substances will stimulate free nerve endings are Histamines, anaerobic metabolites and chemical enzymes, osmotic pressure development. It will reflect in swelling, cramps or muscle spasm which lead to reduced muscle activity. [16] Several researchers tried to explain theory behind the DOMS through their studies. The Proposed models of theories are, lactic acid theory, muscle spasm, connective tissue damage, inflammation, muscle damage, enzyme efflux theory and others.[17]

\section{Inflammation Theory}

A cardinal sign of DOMS is inflammation. When a structural damage occurs initially inflammation is noticed. Eccentric exercise leads to plasma membrane injury, in causes inflammatory reaction. Enzymatic activity will lead to degradation of macromolecule following injury. Inflammatory response will further cause autocoid leukotriene synthesis. Increase in leukotrienes will generate free radicals, that exacerbate injury to the plasma membrane. It will result in fluid movement to the cells and blood stream causing swelling, pain sensation. [18]

\section{Excess metabolite Theory/Lactic Acid Theory}

Following an exercise lactic acid production will be seen. Accumulation of metabolic by products may lead to noxious stimulus and the perception of pain is seen. But this theory is largely rejected, as it may create mild acute pain following fatigue by extensive workout but cannot be reason for delayed pain. [19]

\section{Muscle injury Theory}

Continuous eccentric contractions will lead to wear and tear of the muscle fibres, results in structural changes to the muscle fibres. Small injury also initiates white blood cells to the area causing inflammation. It will activate the discharge of histamine and prostaglandins. This theory was initially explained by Hough. Microscopic changes were seen. Mechanical disruption of structural components will stimulate nociceptors thus leading to the pain. This will be observed by increase in creatine kinase (CK) levels in blood streams. ${ }^{20]}$

\section{Muscle Spasm Theory}

It was proposed by De Vries in 1961. This theory is based on the hyperbolic resting muscle activation. It will cause spasm to the local activated muscle tissue; initiates pain vicious cycle. Stimulation free nerve ending will cause reflex cramp and prolonged ischaemic mechanism.[21]

\section{Enzyme outflow Theory}

This is the most recent theory developed by Armstrong. High intensity eccentric exercises will cause an injury to the sarcolemma, disruption of structural macromolecules occur in myofibrils. Structural changes due to high mechanical forces will lead to influx of calcium ions from instetitium and inhibits respiration at mitochondrial level. Intracellular components in interstitium and plasma increase thus drawing monocytes that convert to scavenger cell and activate mastocyte and histocyte within the space of injury. Armstrong hypothesise that the build-up of amine, kinins and K within the interstitium stirred free nerve endings of cluster IV nerve cell, that activated the nociceptors and leading to the feeling of DOMS.[22] 


\begin{tabular}{|c|c|c|c|}
\hline $\begin{array}{l}\text { Sl. } \\
\text { No. }\end{array}$ & Author & $\begin{array}{c}\text { Year of } \\
\text { the } \\
\text { Study }\end{array}$ & Remarks \\
\hline 1. & Markus et.al [23] & 2021 & $\begin{array}{l}\text { The purpose of this study was to analyse exercise induced muscle damage (EIMD). } \\
\text { This study worked on the various factors to know the impact on the performance. } \\
\text { The considered factors were sex, age, nutrition, fitness level, genetics, and } \\
\text { familiarity with exercise task. The researcher also focused on the available } \\
\text { assessment techniques for EIMD. Researcher concluded that nutritional strategies } \\
\text { would help in recovery from EIMD. }\end{array}$ \\
\hline 2. & Diep susan [24] & 2019 & $\begin{array}{l}\text { The study suggested DOMS is not an acute type of pain as it takes } 24-72 \text { hours to } \\
\text { show symptoms. This study suggests, as main cause of DOMS is repetitive eccentric } \\
\text { force. Muscle groups which are not accustomed to this amount of sudden force for } \\
\text { a long period of time will suffer soreness. The muscle fibres will undergo } \\
\text { microtears on a cellular level that are not detectable with conventional ultrasound, } \\
\text { however, the overall appearance of the muscle will appear different in size, } \\
\text { echogenicity and texture which can be seen on ultrasound. }\end{array}$ \\
\hline 3. & $\begin{array}{l}\text { Thilo Hotfiel } \\
\text { et. al [25] }\end{array}$ & 2018 & $\begin{array}{l}\text { This study mainly focused to understand the current findings regarding the } \\
\text { damaging mechanisms as well as the pathophysiology of DOMS and its diagnostic } \\
\text { evaluation. Recently considered primary mechanism is the damage of ultra- } \\
\text { structural damage of muscle cells due to unfamiliar sporting activities or eccentric } \\
\text { exercise, which leads to further protein degradation, apoptosis, and local } \\
\text { inflammatory response. The symptoms developafter some time of injury. Soreness } \\
\text { will peaks up at } 48-72 \text { hours post exercise because of local and systemic } \\
\text { physiological responses. }\end{array}$ \\
\hline 4. & $\begin{array}{l}\text { Karasiak } \\
\text { et.al [26] }\end{array}$ & 2018 & $\begin{array}{l}\text { The purpose of this study was to analyze the effect of exercise-induced muscle } \\
\text { damage (EIMD) efficiency and in aerobic and anaerobic cycling performances. } 9 \\
\text { cyclists were assessed in the laboratory. } 5 \text { session were done. The results } \\
\text { suggested, there were no significant difference in } \dot{V} \text { o2, Vंco2, and heart rate in } \\
\text { submaximal exercises, neither in time trial. No differences were observed in the } \\
\text { Wingate tests. The researcher concluded with this study as trainers must be } \\
\text { cautious about EIMD after strength training sessions. }\end{array}$ \\
\hline 5. & $\begin{array}{l}\text { DeSimone, } \\
\text { Grace T. [27] }\end{array}$ & 2017 & $\begin{array}{l}\text { The researcher suggests taking quality as priority than quantity. During running or } \\
\text { downhill activities DOMS occur because the muscle is stressed during its } \\
\text { lengthening phase (eccentric contraction), and that will cause more soreness. } \\
\text { Researcher suggested, soreness is the indicator to know the overload and } \\
\text { frequency of the workload. In case of soreness immediate medical attention is } \\
\text { required. }\end{array}$ \\
\hline 6. & $\begin{array}{l}\text { Mizumura K, } \\
\text { Taguchi T [28] }\end{array}$ & 2016 & $\begin{array}{l}\text { In this study, researcher found activation of the B2 bradykinin receptor nerve } \\
\text { growth (NGF) pathway and activation of COX-2 glial cells line derived neurotropic } \\
\text { factor (GDNF) pathway. Researcher explained DOMS as the mechanical } \\
\text { hyperalgesia. These neurotropic factors were produced by muscle fibres and } \\
\text { satellite cells. The results of this study, shows that muscle fibre damage instead of } \\
\text { NGF and GDNF produced by muscle fibre cells play crucial roles in DOMS. }\end{array}$ \\
\hline 7. & $\begin{array}{l}\text { Kazue Kanda } \\
\text { et. al[29] }\end{array}$ & 2013 & $\begin{array}{l}\text { Researchers aim of the study is to determine the relationship among delayed onset } \\
\text { muscle soreness, muscle damage and inflammatory responses to eccentric exercise } \\
\text { and investigated the underlying mechanisms for soreness. } 9 \text { healthy males' blood } \\
\text { and urine samples were analysed to know the migratory activity. Results suggested } \\
\text { neutrophils mobilised in the circulation and positive correlation between the } \\
\text { exercise induced increased in neutrophil migratory activity and increases in Mb, } \\
\text { suggests the muscle damage and inflammation. }\end{array}$ \\
\hline 8. & Zubian Veqar[5] & 2013 & $\begin{array}{l}\text { In this study DOMS was explained by a combination of theories such as } \\
\text { inflammatory theory, connective tissue theory, muscle injury theory, excess } \\
\text { metabolic theory, enzyme e outflow theory and muscle spasm theory. Researcher } \\
\text { suggested physiotherapy treatment is the most effective form of management for } \\
\text { DOMS. }\end{array}$ \\
\hline 9. & $\begin{array}{l}\text { Close GL } \\
\text { et.al. [30] }\end{array}$ & 2005 & $\begin{array}{l}\text { Researcher stated that when an untrained skeletal muscle performed exercise, } \\
\text { resulted in discomfort that did not evident until } 8-10 \mathrm{~h} \text { post-exercise. The } \\
\text { researcher suggests that free radicals act as signalling molecules, specifically } \\
\text { activating redox sensitive transcription factors, which are necessary for muscle } \\
\text { regeneration and adaptation following damage. Researcher concludes the study; } \\
\text { free radicals will play a key role in causing DOMS. }\end{array}$ \\
\hline
\end{tabular}




\begin{tabular}{|c|l|c|l|}
\hline 10. & $\begin{array}{l}\text { Cheung, K. } \\
\text { et. al. [21] }\end{array}$ & 2003 & $\begin{array}{l}\text { DOMS Greater perception of muscle soreness tends to be associated with high } \\
\text { intensity exercise. The impact of DOMS on athletic performance has not been well } \\
\text { researched. Significant reductions in peak torque can occur for up to 8 days } \\
\text { following eccentric exercise. Impact of DOMS on athletic performance and different } \\
\text { treatment strategies and theories were well explained in the study. }\end{array}$ \\
\hline 11. & $\begin{array}{l}\text { Nosaka K. } \\
\text { et.al. [31] }\end{array}$ & 2002 & $\begin{array}{l}\text { This study was done to analyse the relationship between the DOMS and the } \\
\text { indicators of muscle damage after the eccentric exercises. Muscle soreness (SOR) } \\
\text { was evaluated by a visual analogue scale (a 50-mm line, 0: no pain, 50: extremely } \\
\text { painful) when the elbow flexors were palpated (SOR-Pal), flexed (SOR-Flx) and } \\
\text { stretched (SOR-Ext). This study concludes that use of DOMS is a poor reflector of } \\
\text { eccentric exercise-induced muscle damage and inflammation, and changes in } \\
\text { indirect markers of muscle damage and inflammation are not necessarily } \\
\text { accompanied with DOMS. }\end{array}$ \\
\hline 12. & $\begin{array}{l}\text { Armstrong } \\
\text { et.al. [32] }\end{array}$ & 1984 & $\begin{array}{l}\text { In this study several causative factors for the DOMS were reviewed. High } \\
\text { mechanical forces, structural damage, progressive deterioration of the } \\
\text { sarcolemma, accumulation of histamine, kinies and potassium mechanisms were } \\
\text { explained in the study. }\end{array}$ \\
\hline
\end{tabular}

\section{IMPACT OF DOMS ON ATHLETIC PERFORMANCE}

As a result of eccentric activity, DOMS with structural damage to muscle and connective tissue will result in muscular function alteration and joint range of movement. In elite population this kind of soreness, alteration mechanism will show the significant changes in the performance. [34] Several studies have shown the changes in strength and power during DOMS, these alterations are seen mostly in eccentric muscle contractions. [33]

\section{TREATMENT STRATEGIES}

DOMS symptoms and impact on athletic performance was investigated in many studies. After DOMS subsides restoring the maximal function of the muscles as rapidly as possible is the most important aim of the physiotherapist. [18] Treatment strategies would be first preventive measures and therapeutic treatment strategies to lower the DOMS impact and restore the performance of an athlete. Anti-inflammatory drugs will help alleviate the pain and inflammation. Physiotherapy management will include cryotherapy, stretching exercises, ultrasound, electrical current techniques, massage, compressive therapy, hyperbaric oxygen along with exercises.

\section{CONCLUSION}

DOMS occurs as a reaction to the sudden, strenuous, unaccustomed activity of the muscle, it results in pain, tightness, reduced range of motion and edema. DOMS in not only occurs in sports population, also seen in normal population who tries an unfamiliar activity. Source of DOMS is high intensity eccentric exercises. This review is done to focus on the mechanism and various theories which are explaining about DOMS development. The DOMS has an impact on the athletic performance. Although various theories are saying the development, impact on performance but has not well researched. A paucity is seen in the development of new theories in development or preventive methods of DOMS. Recent literature is less on the mechanism or theories. Researcher if focuses on more on the various new methods of preventive and therapeutic measures for reducing DOMS occurrence and impact, it will help a wide range of athletic/sports population, would be applicable for major health sector.

\section{REFERENCES}

[1] Miles, M. P., \& Clarkson, P. M. Exercise-induced muscle pain, soreness, and cramps. The Journal of sports medicine and physical fitness. 1994; 34(3): 203-216.

[2] Armstrong RB. Mechanisms of exercise-induced delayed onset muscular soreness: a brief review. Med Sci Sports Exerc.1984; 16 (6): 529-38.

[3] Byrnes WC, Clarkson PM. Delayed onset muscle soreness and raining. Clin Sports Med 1986; 5 (3): 605-14.

[4] Maggie, J. Cleak and Eston roger G. Muscle soreness, swelling, stiffness and strength loss after intense eccentric exercise. BJSM. 1992; 26(4): 267-272.

[5] Zubia Veqar. Causes and Management of Delayed Onset Muscle Soreness: A Review. Elixir Human Physio. 2013; 55: 13205-13211.

[6] Jones DA, Newham DJ, Round JM, et al. Experimental human muscle damage: morphological changes in relation to other indices of damage. J Physiol.1986; 375: 435-48.

[7] Stauber WT. Eccentric action of muscles: physiology, injury, and adaptation. Exercise and sport science reviews. 1989; 157-86.

[8] Eston RG, Lemmey AB, McHugh P, et al. Effect of stride length on symptoms of exercise-induced muscle damage during a repeated bout of downhill running. Scand J Med Sci Sports. 2000; 10 (4): 199-204.

[9] Eston RG, Critchley N, Balzopoulos V. Delayed onset muscle soreness, strength loss characteristics and creatine kinase activity following uphill and downhill running. The contribution of sport science, sports medicine and coaching to performance and excellence. 1993: 10-11 
[10] Francis K, Hoobler T. Delayed onset muscle soreness and decreased isokinetic strength. J Appl Sport Sci Res. 1988; 2 (2):20-3.

[11] Jones DA, Newham DJ, Round JM, et al. Experimental human muscle damage: morphological changes in relation to other indices of damage. J Physiol 1986; 375: 435-48

[12] Komi, P.V. and Viitasalo, J.K. Changes in motor unit activity and metabolism in human skeletal muscle during and after repeated eccentric and concentric contractions. Acta Physiological Scandinavica, 1997;100: 246-54.

[13] Donnelly, A.E., Clarkson, P.M. and Maughan, R.J. Effects of light exercise on exercise damaged muscle. Medicine and Science in Sports and Exercise.1988; 20: S75.

[14] Abraham, W.M. Factors in delayed onset muscle soreness. Medicine and Science in Sports and Exercise. 1977; 9: 11-20.

[15] Armstrong R.B. Mechanism of exercise induced muscle fibre injury. Sports Medicine. 1991; 12(3): $184-207$.

[16] Mc Aedle WD, Katch FI, Katch VL. Essentials of exercise physiology, 2000; 2nd edition, Baltimore: Lippincott, Williams and wilkin.

[17] Gulick DT, Kimura IF. Delayed onset muscle soreness: what is it and how do we treat it? J Sport Rehab 1996; 5: 234-43.

[18] Conolly D.A.J, S.P. Sayers, M.P. McHugh. Treatment and prevention of Delayed Onset Muscle Soreness. J Strength Cond Res 2003;17(1):197-208.

[19] Cazorla G, Petibois C, Bosquet L, et al. Lactate et exercice: mythes et realites. Rev Sci Tech Activ Phys Sport (Grenoble). 2001; 22 (54): 63-76.

[20] Newham DJ, Jones DA, Edwards RH. Large, delayed plasma creatine kinase changes after stepping exercise. Muscle Nerve. 1983; 6(5):380-5.

[21] Cheung K, Hume P, Maxwell L. Delayed onset muscle soreness: treatment strategies and performance factors. Sports Med. 2003; 33(2):145-64.

[22] Armstrong RB. Mechanisms of exercise-induced delayed onset muscular soreness: a brief review. Med Sci Sports Exerc. 1984;16(6): 529-38.

[23] I. Markus, K. Constantini, J. R. Hoffman, S. Bartolomei, Yftach Gepner, Exercise-induced muscle damage: mechanism, assessment and nutritional factors to accelerate recovery. European journal of applied physiology.2021;121(4):969992. doi.org/10.1007/s00421-020-04566-4.

[24] Susan Diep, DOMS, Ultrasound in Medicine \& Biology.2019; Volume 45: Number S1.

[25] Thilo Hotfiel et. Al, Advances in Delayed-Onset Muscle Soreness (DOMS): Part I: Pathogenesis and Diagnostics, muscle injuries: biology and treatment,2018;32(04): 243-250.

[26] Karasiak, Fábio C.; Guglielmo, Luiz Guilherme A. Effects of Exercise-Induced Muscle Damage in Well-Trained Cyclists' Aerobic and Anaerobic Performances, Journal of Strength and Conditioning Research: September 2018; Volume 32(9): 2623-2631.doi: 10.1519/JSC.0000000000002522.

[27] DeSimone, Grace T. B.A. SHAREABLE RESOURCE, ACSM's Health \& Fitness Journal: May/June 2017; Volume21(3): 5. doi: 10.1249/FIT.0000000000000287.

[28] Mizumura K, Taguchi T. Delayed onset muscle soreness: Involvement of neurotrophic factors. J Physiol Sci. Jan 2016;66(1):43-52. doi: 10.1007/s12576-015-0397-0. PMID: 26467448.

[29] Kanda K, Sugama K, Hayashida H, Sakuma J, Kawakami Y, Miura S, Yoshioka H, Mori Y, Suzuki K. Eccentric exerciseinduced delayed-onset muscle soreness and changes in markers of muscle damage and inflammation. Exerc Immunol Rev. 2013; 19:72-85. PMID: 23977721.

[30] Close GL, Ashton T, McArdle A, Maclaren DP. The emerging role of free radicals in delayed onset muscle soreness and contraction-induced muscle injury. Comp Biochem Physiol A Mol Integr Physiol. Nov 2005; 142(3): 257-66. doi: 10.1016/j.cbpa.2005.08.005. Epub 2005 Sep 8. PMID: 16153865

[31] Nosaka K, Newton M, Sacco P. Delayed-onset muscle soreness does not reflect the magnitude of eccentric exerciseinduced muscle damage. Scand J Med Sci Sports. 2002; 12:337-346.

[32] Rowlands AV, Eston RG, Tilzey C. Effect of stride length manipulation on symptoms of exercise-induced muscle damage and the repeated bout effect. J Sports Sci 2001; 19 (5): 333-40.

[33] Paddon-Jones DJ, Quigley BM. Effect of cryotherapy on muscle soreness and strength following eccentric exercise. Int J Sports Med 1997; 18: 588-93. 